\title{
Juego, estado del sentir y experiencia en el ritual ${ }^{*}$
}

"Ponencia a ser presentada en el Seminario de Investigación "Problemática Contemporánea de la Imagen", en torno al VI Congreso Internacional de la Asociación Internacional de Semiótica Visual, convocado por la División de Ciencias y Artes para el Diseño (UAM-A), Centro Nacional de las Artes (CENART) y Centro de la Imagen (CONACULTA), México.

INGRID GEIST

Escuela Nacional de Antropología e Historia - ENAH/México 


\section{Resumo}

El texto centra la discusión en la noción de juego, que la autora estima como uno de los mecanismos rituales encaminados a la disolución de las estructuras significantes. La suspensión de la signicidad inaugura e impregna la fase liminar del rito en la cual se abre un horizonte que permite a los actores rituales sumergirse potencialmente en un estado del sentir. Con base en la semiótica de Charles S. Peirce, se plantea este estado del sentir como condición lógica para el proceso de semiosis, reconociendo a su vez la primacía fenomenológica de la experiencia.

\section{Palavras-chave}

juego, mito, semiosis

\section{Abstract}

The paper pays attention to the discussion on the idea of playing considering it as one of the ritual mechanisms pointing to dissolution of the signifying structures. The suspension of signicity inaugurates and permeates the liminal phase of the rite opening a horizon that permits the ritual actors potentially merging themselves into a state of feeling. On the basis of semiotics of Charles C. Peirce, the author stresses the point that this very state of feeling is the logical condition of semiosis, recognizing at the same time the phenomenological primacy of experience.

\section{Key words}

game, myth, semiosis 


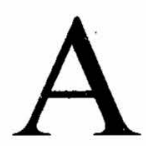

1 refutar las críticas formuladas a su obra, Claude LéviStrauss rechaza la objeción de que haya desconocido lo afectivo. A su juicio, no se trata de abandonarse a lo inefable sino de colocar los estados afectivos en su lugar preciso.

No es pasar por alto los estados afectivos el ponerlos en su verdadero lugar, o-lo cual se reduce a lo mismo-en el único lugar donde resulte posible comprenderlos -no anterior a toda captación del mundo por el pensamiento sino al contrario, posterior y subordinado a tal captación y marcado desde el instante en que la mente aprehende la antinomia inherente a la condición humana entre dos sujeciones ineluctables: la del vivir y la del pensar. (Lévi-Strauss, 1976, p. 615)

Esta oposición entre el vivir y el pensar, Lévi-Strauss la equipara con la oposición entre el rito y el mito, revertiendo la crítica en el entendido de que, en su opinión, se ha omitido definir la especificidad del ritual frente al mito. La reflexión lévi-straussiana desemboca en una serie de afirmaciones sobre el.ritual que considero de sumo interés, no obstante los sesgos valorativos que permean sus aseveraciones. Según Lévi-Strauss, el ritual alimenta "la ilusión de que es posible remontarse a contracorriente del mito, rehacer [lo] continuo a partir de lo discontinuo"; el ritual es una "tentativa consternada, siempre destinada al fracaso, de restablecer la continuidad de lo vivido".(Ibid., p. 609)

Las reflexiones del antropólogo parten de una formulación empírica, según la cual el rito se compone de "palabras proferidas, gestos hechos, objetos manipulados" (Ibid., p. 606) esto es, se 
compone de actos que también se realizan en la vida cotidiana y, por lo tanto, hay que preguntar por la línea divisoria que separa las actividades rituales de las cotidianas. Refiriéndose a las palabras proferidas, Lévi-Strauss subraya el carácter frecuentemente ininteligible de éstas en el ritual -puesto que no se trata de trasmitir o intercambiar información entre los actores rituales-y concluye que "el ritual pone gestos y cosas en lugar de su expresión analítica." "Los gestos ejecutados, los objetos manipulados son otros tantos medios que el ritual se otorga para evitar hablar."(Ibid., p. 607). El carácter anti-analítico del ritual se acentúa por los procedimientos de fragmentación y repetición, por medio de los cuales

el rito no refuerza sino que invierte el recorrido del pensamiento mítico que, por su parte, escinde el mismo continuo en grandes unidades distintivas entre las cuales instituye separaciones. El ritual trata vanamente de reducir estas unidades hasta llegar a un valor limite que no puede jamás alcanzar: si no se aboliría el pensamiento mismo. Esta tentativa consternada, siempre destinada al fracaso, de restablecer la continuidad de lo vivido desmantelado por efecto del esquematismo que en su lugar puso la especulación mítica, constituye la esencia del ritual.(Ibid., p. 609).

En tanto que el mito da resueltamente la espalda a lo continuo para cortar y desarticular el mundo por medio de distinciones, de contrastes y de oposiciones, el rito sigue un curso inverso: partido de las unidades discretas que le son impuestas por esta conceptualización previa de lo real, corre en pos de lo continuo y procura alcanzarlo, por mucho que la ruptura inicial impuesta por el pensamiento mitico haga imposible la tarea por siempre. [...] El ritual, pues, no procede de una reacción espontánea de lo vivido [...] sino al revés: es decir una segunda intención nacida del temor de que a partir de una visión esquemática y conceptualizada del mundo [...] no consiga el hombre dar con el camino de lo vivido.[...] El rito no crea los axiomas ni las leyes, más 
bien se dedica, si no renegar de ellos, cuando menos a obliterar temporalmente las distinciones y oposiciones que dictan, haciendo aparecer entre éstas toda suerte de ambigüedades, de componendas y de transiciones. (Ibid., p. 614). ${ }^{1}$

Con esta última afirmación, Lévi-Strauss parecería aproximarse a la comprensión del proceso ritual por parte de Victor Turner que considera la liminaridad - la fase intermedia de la indeterminación, de la ambigüedad y la paradoja - como el núcleo del esquema trifásico de separación-limen-agregación, en el cual la transición hace posible la transformación. Si bien Turner es uno de los autores contra quien va dirigida la argumentación lévi-straussiana, no obstante, ambos antropólogos concuerdan en esta idea de transición, a la vez que esta coincidencia no buscada y ciertamente superficial contiene grandes discrepancias. Para Lévi-Strauss, la ilusión del ritual de recuperar lo vivido o lo continuo está diametralmente opuesta al trabajo de categorización de los mitos cuyas transformaciones analizadas a lo largo de su vasta obra conservan siempre el principio estructural del mundo clasificado según términos binarios, aunque el autor aduzca frecuentemente la idea de que los mitos se construyen sobre los residuos dejados por los efectos destructivos de la diacronía. Quiere decir que no hay lugar en su propuesta teórica para lo aestructural y las transformaciones se reducen a cambios topológicos en un mundo perennemente estructurado. En cambio, para Turner, la transición liminar -el modo subjuntivo de lo posible-es un horizonte de libertad, creatividad e innovación y también es el horizonte sobre el cual emerge el significado.

1. Lévi-Strauss continúa diciendo que el ritual "responde al modo como el hombre piensa el mundo", oponiendo la risa y la ansiedad, considerando que la última es la que caracteriza el ritual. "La nisa traduce una gratificación inesperada de la función simbólica." La ansiedad es "resultante de una frustración de la función simbólica". (Ibid., p. 615). Por un lado, habría que cuestionar la idea de "frustración" que en la comprensión lévistraussiana obviamente es coherente con el planteo del ritual como tentativa destinada necesariamente al fracaso de restablecer lo continuo. Por otro lado, la risa es ingrediente esencial del ritual. Cf., por ejemplo, el relato de Ranjini Obeyesekere sobre un ritual exorcista que, en su fase liminar, comprende danzas de los demonios, los cuales se convierten en figuras cómicas en la transición hacia la agregación, in: Schechner y Appel (1990). Véase también Bruce Kapferer (in: Turner y Bruner, 1986) que considera la risa como un signo de reintegración en el mundo normal. 
Para explicar el proceso ritual, Turner parte de la idea de que todo rito es un proceso de transformación, distinto de la ceremonia que es un acto de confirmación, donde por transformación se entiende un cambio cualitativo. Desde esta perspectiva, todo rito es un rito de paso, ya sea en sentido restringido, como rito de crisis vital, por ejemplo el paso de la infancia a la mayoría de edad, o como rito de aflicción, en el caso de enfermedades o infortunios que aquejan a los actores sociales; ýa sea en sentido amplio, como rito de cambio de poder o de investidura de un rol dentro de la jerarquía social y el pasaje de una estación natural culturalmente definida a otra, lo cual incluye los ritos agrícolas y calendáricos. En todos los casos se trata de la transición de un individuo o grupo social de la visibilidad a la invisibilidad estructural y el retorno de la invisibilidad a la visibilidad estructural. El interés de Turner se centra especialmente en la fase liminar donde el individuo o grupo se describe como carente de insignias y propiedades sociales, como muerto y vivo, y como no-muerto y no-vivo, al mismo tiempo. Se trata de un estado transicional de indeterminación, durante el cual los individuos "ya no están clasificados y, al mismo tiempo todavía no están clasificados" (Turner, 1980, p. 106).

Su condición propia es la de la ambigüedad y la paradoja. [...] Lo liminar puede tal vez ser considerado como el NO frente a todos los asertos estructurales positivos, pero también al mismo tiempo como la fuente de todos ellos, $y$, aún más que eso, como el reino de la posibilidad pura, de la que surge toda posible configuración, idea y relación. (Ibid., p. 107).

La idea de la liminaridad como "reino de la posibilidad", Turner la desarrolla en obras posteriores con base en una metáfora lingüística: la posibilidad como modo subjuntivo. Distingue entre dos modos de la cultura: uno indicativo y otro subjuntivo (Turner, 1988, p. 41), lo cual es una reformulación de su propuesta inicial de distinguir entre estructura y anti-estructura o communitas como dos modelos de sociedad (Turner, 1989 ). ${ }^{2}$ La liminaridad -junto con communitas-

2. Véase los capítulos III, IV y V. Me baso en la edición alemana. La obra está traducida al español: El proceso ritual, Taurus, Madrid, 1988. 
es una forma de anti-estructura, como tal es la fase del ritual en la cual se asoma un modelo alternativo de sociedad, aun cuando las acciones rituales se rigen según reglas firmemente establecidas por la tradición y la costumbre. La estructura temporal del rito, entonces, parte del espacio-tiempo estructurado del modo indicativo de la vida social para, a través del rito de separación o la disolución de la topología social, dar cabida a un espacio-tiempo posible del modo subjuntivo de la vida social, que se caracteriza por su liminaridad. Desde el modo subjuntivo, a través del rito de agregación o el proceso generador de la topología social, se vuelve a instaurar un modo indicativo de las relaciones sociales. La fase liminar se presenta predominantemente en el modo subjuntivo de la cultura, el modo de lo posible: pudiese ser, como si; es el terreno de la hipótesis, la fantasía, la conjetura y el deseo. La liminaridad puede describirse como un caos fértil, una fuente de posibilidades, un esfuerzo por generar nuevas formas y estructuras, un proceso de gestación, un embrión de modos apropiados para la existencia posliminar. La liminaridad aparece como el manantial de un meta-poder excesivo, como, por ejemplo, en la acción simultánea de liberación y disciplinamiento del cuerpo que conduce al trance.

La estructura temporal del rito

El ritual se deriva del núcleo subjuntivo, liminar, reflexivo, exploratorio del drama social, donde las estructuras, dentro de las cuales el grupo vive su mundo social, son replicadas, desmembradas, remembradas, remodeladas y convertidas en significativas, de manera verbal o no verbal (Turner, 1988, p. 42). La liminaridad es producto de una "desconstrucción" de la topología social y las estructuras significantes y al mismo tiempo condición para el proceso generador

3. Uso el término de desconstrucción en un sentido meramente descriptivo. Como se verá más adelante, se refiere a la fase del proceso ritual que se orienta hacia la suspensión de la signicidad y del tiempo cosmológico. No me adhiero con ello al desconstruccionismo, por ejemplo, de Jacques Derrida. Mier (1989) señala que "la tarea desconstructiva evoca el rastro, asume radicalmente la imagen del signo no como restauración de la presencia, sino como el residuo de una errancia." (p. 236). Mi intención, en cambio, es la de mostrar como a,través de los mecanismos desconstructivos o desarticuladores, el ritual abre la posibilidad de un campo de presencia a partir del cual emerge el sentido. Pienso ahí en la manera de cómo Jean 
preliminar

poṣliminar

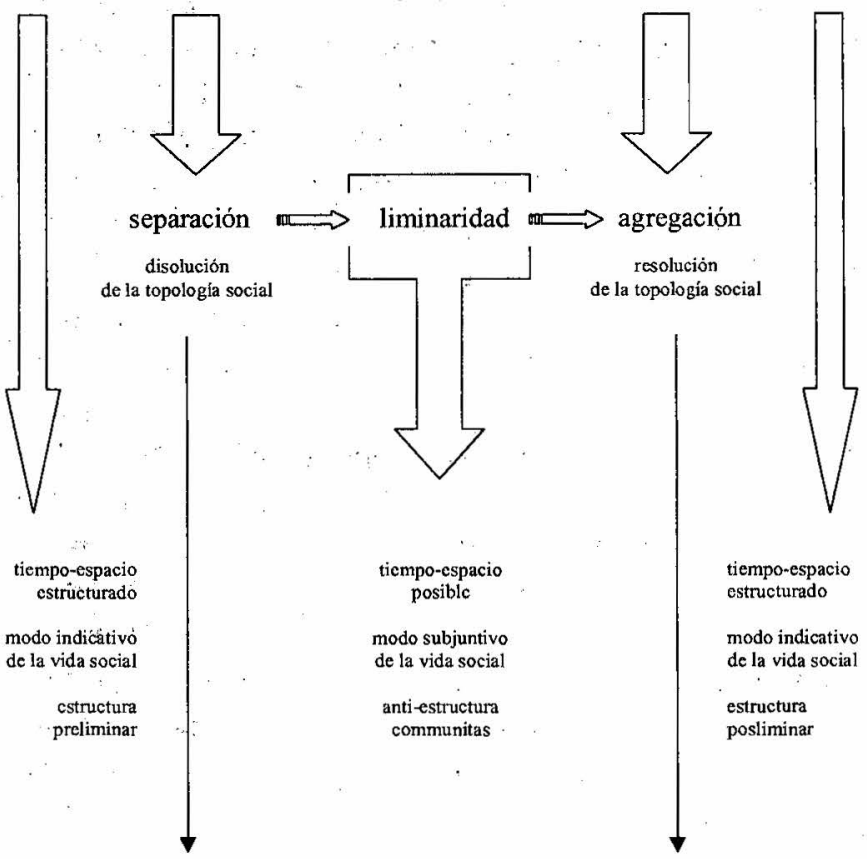

de una nueva topología social y de las nuevas estructuras significantes. Al respecto, Turner aborda repetidas veces la noción del juego. Señala que el juego no cabe dentro de nada particular, trasciende y rechaza cualquier tipo de localización, ubicación o fijación. El juego es comparable al trickster del mito. ${ }^{4}$ Estas afirmaciones permiten

Françoise Lyotard se refiere a la música en tanto que "arte producido por el tiempo", que desemboca en una "resolución": "la terminación de una tensión, incluso una disonancia, entre sonidos o secuencias de sonidos, gracias a su combinación final en un acorde común ". Parafraseando a Lyotard, el ritual es una pieza de tiempo que debe resolverse. "Es como si el tiempo y el material sonoro que lleva consigo tuvieran que cerrarse definitivamente tras unas crisis que seria[n] en realidad el momento del "tiempo mismo." (Lyotard, 1992).

4. Véanse los artículos "Body, Brain, and Culture": (Turner, 1985); y "The New Neurosociology"; op. cit., pp. 275-289. La noción del juego como trickster se encuentra en "Body, Brain, and Culture", op. cit., pp. 262-264. El mismo artículo aparece también en The Anthropology of Performance, op. cit., pp. 156-178. 
considerar el juego como uno de los procedimientos -otros serían tal vez la celeridad y la ritmicidad-por medio de los cuales se desconstruyen las estructuras significantes. Ritual y juego, por lo tanto, no se oponen, como diría Lévi-Strauss quien resume sus reflexiones respectivas tanto que las reglas son las mismas para todos los participantes y simulan una igualdad entre éstos, a partir de la cual se engendra una asimetría que "se deriva inevitablemente de la contingencia de los acontecimientos, dependan éstos de la intención, del azar, o del talento" (Ibid., p. 58). En el ritual, en cambio, aun cuando éste lleva aspectos lúdicos, se trata de "hacer pasar a todos los participantes al lado del bando ganador, por medio de acontecimientos cuya naturaleza y ordenamiento tienen un carácter verdaderamente estructural" (Ibid., p. 59). Efectivamente, el juego produce acontecimientos que, según el esquema trifásico del ritual, tendrán que ubicarse en la fase liminar, lo cual suscita la duda acerca de la naturaleza estructural del acontecimiento, incompatible, por lo demás, con la idea de contingencia aducida por el propio Lévi-Strauss, y la duda de que sean realmente conjuntos acontecimentales lo que el ritual descompone y recompone, sino estructuras significantes. Incluso, en el caso de los ritos de aflicción que se ejecutan, al estar los hombres confrontados con los infortunios ocurridos en su mundo, lo que se descompone es la categoría orden/desorden para reingresar a un mundo en el cual el término marcado de la categoría se desplaza del desorden al orden.

Según Turner, el juego se sustrae de una definición y Richard Schechner concuerda con él al abogar por aplazar cualquier intento de definición. Schechner menciona como uno de los aspectos centrales del juego el de la creación de realidades múltiples, la cual relaciona con la noción de Maya del pensamiento hindú. Integra en su reflexión la caracterización de Maya de O'Flaherty como poder realizador del mundo fenoménico. El juego de Maya es un acto de creación de múltiples realidades las cuales se caracterizan por ser efímeras, transitorias y porosas. Según Schechner, no es preciso aceptar el universo de Maya como empíricamente verdadero para darse cuenta de la fertilidad de la noción. No se trata de una versión reduccionista que convierte el mundo en escenario, sino de un sistema dinámico sin 
centro fijo, sin punto de reposo y sin referente absoluto (Schechner, 1995 , pp. 24-44).

Lo que Schechner entiende por el juego de Maya, se deriva, según la cosmología hindú, de la actividad libre e incondicionada de Sakti, el segundo de 36 principios que describen la creación del mundo como un proceso de contracción de la conciencia universal. El primer principio presenta esta conciencia en su estado primordial, como totalmente expandida y en reposo. Es el aspecto masculino representado por Siva. El segundo principio, Sakti, el aspecto femenino, entiende la conciencia como una energía, una potencialidad pura de ponerse en movimiento e iniciar el proceso de creación que atraviesa por otros tres principios de potencialidad pura: voluntad ilimitada (Sadakhya), conocimiento ilimitado (Isvara) y acción ilimitada (Suddhavidya). Maya se coloca en el sexto lugar, es el primer principio puro-impuro, la fuerza a partir de la cual se inicia el proceso de contracción de la conciencia. Le siguen cinco principios que expresan los poderes de limitación de Maya: individuación (Kala), conocimiento limitado (Vidya), voluntad limitada (Raga), tiempo (Kala) y espacio (Niyati), que conducen a la oposición entre espíritu (Purusa) y materia (Prakrti) correspondientes a los principios duodécimo y decimotercero (Singh, 1979 , pp. XII-XXVIII: I). ${ }^{5}$

En el pensamiento hindú, Maya es un poder diferenciador y clásificador, la ilusión de las diferencias, como tal, podría ser una metáfora sugerente para describir el proceso generador desde el fondo indiferenciado de la liminaridad hasta la constitución de una topología social. Maya bien podría entenderse como una metáfora para la semiótica, ${ }^{6}$ para el proceso de significación que instaura las determinaciónes discretas. El juego de Maya es el juego recurrente de crear mundos, realidades múltiples, donde los sistemas clasificadores se sobreponen, se atraviesan y se contradicen hasta producir

5. The tattvas of the universal experience, II. The tattvas of the limited individual experience, III. The tattvas of the limited individual, IV. The tattvas of mental operation, V-VII. The tattvas of sensible experience y VIII. The tattvas of materiality. El proceso de contracción de la conciencia o manifestación objetiva del mundo prosigue por los principios impuros y según el régimen de los tres factores constitutivos del mundo material.-pureza (Sattva), acción (Rajas) e inercia (Tamas) - hasta manifestarse los cinco elementos, los últimos de los 36 principios, 'que son éter, aire, fuego, agua y tierra.

6. Véase la yuxtaposición de Maya y "clasificación" en Barthes, 1981, p. 101. 
probablemente un efecto destructor. Es, sobre todo, este efecto destructor que nos interesa, aunque consideramos necesario distinguir dos tipos de actividades lúdicas en el ritual: un primero que crea esas múltiples realidades hasta borrar los límites entre los términos -hasta fundir las categorías- y un segundo que se presenta como una escenificación del, orden invertido, como una suerte de rito de agregación en el cual las bufonadas de los actores rituales introducen la distancia estética, como diría Schechner; y las risas, con las cuales las bufonadas son respondidas, indican la gratificación de la función simbólica. ${ }^{7}$

Esta doble faceta del juego se expresa claramente en las acciones rituales de la semana santa de la comunidad cora de Santa Teresa del Nayar. La fase de separación está señalada, a lo largo de la cuaresma, por la proximidad cada vez mayor de la presencia de la judea. Los signos con los cuales los judíos marcan esta presencia, van colocando un cerco alrededor del pueblo que se va cerrando lentamente hasta que, a partir del domingo de ramos, sus acciones rituales van incrementándose, acompañadas a su vez por un aumento de tempo. A lo largo de los días siguientes, con paso veloz, los judíos realizan recorridos sobre un circuito de cruces que circunda la plaza en el exterior. En varias ocasiones, los recorridos se interrumpen, sin que se detenga el movimiento, describiendo una suerte de nudos por el desplazamiento que se ejecuta repetidas veces en torno a los dos centuriones que encabecen el grupo de los judíos: recorriendo breves trayectos en línea recta, de ida y vuelta, a ambos lados de los centuriones, e intercalando movimientos circulares alrededor de ellos, por la mano derecha y por la izquierda. Al entrar en la fase liminar, el día miércoles, los judíos irrumpen por el poniente en la plaza del pueblo, realizando sus carreras en el circuito de las cruces que la circundan en el interior. Los judíos se van convirtiendo en "borrados", según testimonio de los propios santatereseños. En tanto que borrados, son estructuralmente invisibles aunque físicamente visibles

7. Barbara Myerhoff "Transformation of consciousness in ritual performances: some thoughts and questions", in: Schechner y Appel, op. cit., pp. 247-249. Myerhoff plantea la necesidad de tomar en cuenta el problema del distanciamiento, donde, según ella, es el factor lúdico el que lo introduce y que, en ocasiones, puede aparecer como lo ridículo. 
y de una manera ostentosa. Los borrados exhiben sus cuerpos desnudos -salvo los pantalones o calzones enrollados por encima de las rodillasy pintados de negro, el día miércoles, de franjas negras y blancas, el jueves santo, y con el agregado de manchas rojas, el viernes santo. Durante estos días, los borrados cuyo número va acrecentando, circulan en pequeños grupos por todo él poblado, ejecutando pasos rítmicos y realizando así una danza ininterrumpida a lo largo de los tres días. Están tocando flautas y tambores y entonan cantos difamatorios sobre ciertas mujeres, donde en cada encuentro entre dos grupos, uno da la pauta y él otro va tejiendo la trama a su libre albedrío. En estos encuentros entre borrados, armados además con pesados sables de madera, se simulan combates que, en un principio, se presentan como un juego dancístico acompañado por' risas burlonas hasta, en ocasiones, terminar en carcajadas iracundas, seguidas por un golpe fatal asestado sobre el cuerpo o la cabeza de uno de los contrincantes. El juego comporta un riesgo, al borrar las fronteras y hacer que los actores rituales se sumerjan en la intensidad de un mundo de vértigo, en el cual la signicidad -la categoría del bien y del mal-queda suspendida hàsta potencialmente desembocar en una catástrofe que borra el umbral entre vida y muerte. La regulación lúdica descubre su "destino precario". Los actores liminares atraviesan por "una preparación para el juego que es en sí misma un juego" hasta entregarse a un umbral "para experimentar la violencia de una regularidad ausente” (Mier, 1999, pp. 72, 73 y 75).

La otra faceta del juego se expresa en las vaciladas de los. borrados a lo largo de todos los días festivos, colocando un contrapunto al espesor y riesgo de los combates que conllevan un gesto mortal latente, y se manifiesta, el sábado de gloria, en las risas liberadas de la intensidad de la fase liminar y en la escenificación del mundo al revés, que culmina con el acto de sacrificar a los centuriones. Los borrados hablan al revés, se visten con las ropas al revés, imitan las procesiones realizadas los días anteriores, también al revés, y se entregan a una serie de bufonadas jocosas, por medio de los cuales se instaura un doble distanciamiento, uno con respecto a las tensiones y el espesor del sentir de la fase liminar que se resuelven en la experiencia catastrófica del golpe fatal, y otro en relación con el orden del mundo rutinarió. Los judios prosiguen la búsqueda infructuosa del nazareno, iniciada ya el día anterior, y, al ver. 
sus esfuerzos frustrados, se vuelven contra sus cabecillas. El desorden se destruye por su propia fuerza. Los judíos persiguen a los centuriones hasta capturarlos y colgar sus sombreros en el centro de la plaza, como señal de su muerte, la cual es replicada por el acto de quemar a dos monos de zacate que estuvieron en el centro de los últimos excesos del mundo al revés. El ritual termina quemando el zacate en la plaza para dar lugar a un acto purificador -el acto concluyente del rito de agregación-de los judíos que caminan sobre las cenizas calientes y los últimos focos de lumbre que quedan entre éstas.

Los juegos, pues, por un lado, escenifican transitoriamente un estado invertido de las cosas que remite a su contrario, el orden del mundo rutinario, y las risas -como contrapunto y como resolución de la intensidad liminar- expresan, en términos de Lévi-Strauss, 1a "gratificación de la función simbólica", esto es, comportan momentos de reflexividad, como diría Turner. Por otro lado, son juegos de inversión que borran las fronteras, esto es, suspenden las estructuras significantes e introducen, como señala Barbara A. Babcock, un principio de negatividad estética que apunta hacia lo imposible (Babcock, 1978, pp. $16,19,21$ y 24), que, en la propuesta turneriana, sería el mundo subjuntivo de lo posible como un horizonte de incertidumbre sobre el cual emerge lo contingente. Sería aquí donde cabría hablar de la ansiedad evocada por Lévi-Strauss, sin embargo, no en el entendido de una "frustración de la función simbólica" sino como estado afectivo que responde a la situación paradójica de atracción-repulsión que acompaña a los juegos liminares y la disciplina rítmica, encaminados a borrar las distinciones y hacer al sujeto vulnerable.

El agotamiento físico de los cuerpos vacía el afecto, la voluntad y la cognición socialmente moldeados; éstos quedan sin efecto en la entrega a un devenir subterráneo e incierto que, en la superficie, bien puede brotar como un acto violento desmesurado o desplegarse como un silencio que envuelve un sentir y una experiencia intima. La disciplina ritual probablemente habría que definirla como un hacer iterativo que implica tempo y ritmo, hasta apresar al actor ritual, donde esta captura paradójicamente es la condición para la liberación de las determinaciones sociales y significantes. Mientras que las prescripciones y prohibiciones en los estados estructurales de la vida rutinaria implican un reconocimiento 
de la obligatoriédad y:una asunción de la responsabilidad, en el ritual y sobre todo en la:fase liminar, apuntan contrariamente a la suspensión del deber ético para colocar en lugar de éste un deber devocional, un deber que instiga a actuar. Este actuar "puede tener lugar mediante un impulso inmediato" de conformidad ala costumbre que conduce a lo que Charles S. Peirce llama una "retroconsciencia" que, por su parte, puede suministrar la "razón general" para el actuar. Los juegos y los movimientos rítmicamente redundantes de los borrados operan a la manera de una reduplicación iterativa de una constante hasta arrastrar al sujeto fuera de las determinaciones estructurales lo cual, probablemente, puede describirse como una suerte de "repetición sin origen" que provoca un "acontecimiento sin origen" sobre la base de una "memoria sin persona" (Barthes, 1981, p. 109). La disciplina ritual, pues, retorna el sujeto a un estado de cuerpo fenomenal, sumergido en un estado del sentir que Raúl Dorra enuncia como "la presencia de la vida en cuanto tal" o como "el grado cero del vivir", en el cual el cuerpo y el mundo están embragados (Dorra, 1999, p. 257).

En estrecha vinculación con la doble faceta del juego y retomando la idea de una negatividad estética de Babcock, podemos suponer también un carácter doble de la misma: una primera negatividad que se manifiesta en la voluntad desestructurante del juego, hasta arrastrar el sujeto dentro de una deriva incierta y transitoria de un estado del sentir, y una segunda que acontece en el sobrevenir de una experiencia que destruye el sentir. El acaecer no es posible sobre la base de un mundó categorizado, en el cual los signos conservan su integridad, sino requiere de una voluntad que desintegra los signos. En ausencia de los mecanismos rituales para la

8. Retomo aquí, de manera resumida, algunas afirmaciones de Peirce en Las ciencias normativas. Peirce distingue entre el actuar "por obediencia a una ley".y el actuar "bajo la influencia de una vaga personificación de la comunidad". En este segundo caso, el ser humano actúa de conformidad a la costumbre. "La conformidad a una norma puede tener lugar mediante un impulso inmediato. Se transforma entonces en imitación instintiva. Pero el hombre no personifica aqui vagamente la comunidad, sino que él mismo, como se suele decir, se pone en la piel de otro. A este ponerse uno mismo en el lugar de otro lo llamo retroconsciencia." Más adelante, Peirce continúa: "Un hombre puede actuar poniéndose en el lugar de otro y de acuerdo a una razón general suministrada por esta retroconsciencia. [...] Pero esto ya no es conformidad a una norma; es devoción a alguien o a algo. "Peirce, 1988, pp. 292 y 293. Véase también la afirmación de Mier de que "la ley del juego no admite la transgresión porque ésta es la extinción misma del juego. "Podría concluirse entonces que el deber ético implica la posibilidad de su transgresión, en cambio el deber devocional la excluye. (Mier, 2001, p. 7 del manuscrito). 
desconstrucción del universo simbólico (u otros mecanis̄mos que no necesariamente sean del orden ritual), se llegaría a lo que Roger Abrahams llama una experiencia típica:'Al hablar de experiencia, hablamos del flujo continuo de la vida registrado por el filtro de la cultura, quiere decir que identificamos eventos que ya hemos aprendido a interpretar como experiencia, sorpresa o trauma.La tipicidad de la experiencia proporciona un vínculo entre pasado, presente $\dot{y}$ futuro, porque la tipicidad descansa en que otros ya han vivido la experiencia que ocurre en el presente. Los hombres desean optimizar los actos autentificantes, sin embargo, para provocar tales éxpèriëncias, secretamente tienen què gastar gran parte de las energías preparándose para eśtos québrantamientos asombrosos en los cuàles, en realidảd, les sobreviene el cumplimiento de sus expëctaciones. Por lo tanto, puede hablarse de una experiencia dè la experiencia: el reconocimiento de que la vivencia propia es una réplica de vivencias ajenas. $^{9}$

El ritual muestra éfectivamente ese gasto de energías del cual habla Abrahamis, que se presenta como un gran despilfarro a la manerả de un potlatch que destruye los recuŕsos y las energías: una pérdida potencialmente totál como condición de un deslúmbramiento que irrumpe como brecha en el discurso. ${ }^{10}$ Podríamos probablemente -a manera de Jean Duvignaud- häblar del ritual como una "métafisica" en acto" (Duvignaid, 1978; p. 2211) $1{ }^{11}$ que justamente "abre unä brecha en èl discurso" y "es una formá de subversión", induciendo dé esă manera a un espacio-tiempo de "manifestaciones a-estructurales"

9. Abrahams "Ordinary and Éxtraordinary Experience", Turner y Brunér, op. cit., pp. $\mathbf{5 5}$, 60,64 . A mi parecer, lo qué Abrahams describe, es la impósibilidad de una experiencia que, efectivamente, se da en un mundo carente de mecanismos de desconstruir las estructuras significantes. Asocio con este planteamiento las amplias exposiciones de Alfred Schütz sobre el sentido común entendido. como un sistema de construcciones típicas que presupone una "reciprocidad de perspectivas" entre los actores sociales, basada en dos idealizaciones: la de "la intercambialidad de los puntos de vista" y la de la congruencia del sistema de significatividades". (Schütz,1995, pp. 42 ss.)

10.. Véase la referencia a Bataille que Mier (2001; pp. 9-10 del manuscrito) hace en relación con la discusión del juego con base en las reflexiones de Gadamer.

11. Hay que äclarar que el autor aplica la caracterización a la fiesta, no al ritual: Desde la perspectiva de una ruptura entre el trance y la posesión, Duvignaud interroga sobre la posibilidad de un "doble frenesí", por un ladó, "el del trance que conduce a la fiesta", y por otro "el de la posesión que lleva al ritual y la religión". (p. 47) 
(Ibid., p.7). Estas manifestaciones o estados a-estructurales son "zonais de sombra"' "rupturas momentáneas en el transcurso de las cosas", provocadas, por ejemplo, por "Ia rítmica y la danza" y los juegos recurrentes de inversión que "ayudan al cuerpo a despojarse [...] del 'yo' impuesto, pero no sugieren en absoluto ningún otro papel que el de [...] estar en un campo de presencia." (Ibid., pp. 25, 28 y 29). Dicho en términos de Raymundo Mier:

El juego lleva la acción humana hasta la inhumanidad, ahi donde el valor, el intercambio, la ganancia, se disipan para hacer visibles los límites de la propia fuera, del cuerpo, en el enfrentamiento de una incertidumbre a un régimen en el que se atestigua el vacio de la significación que es el vértigo. (Mier, 1999, p. 75).

El juego, pues, se sustrae de una comprensión sistémica que pone el énfasis en una perspectiva meramente constructiva y que plantea los modos de construcción del signifícado como modos homogéneos que remiten a las nociones de estructura, consistencia, coherencia y no-contradicción. Los juegos de la fase liminar del rito y los que conducen a ésta, ponen estos principios fuera de vigencia. Así Louis Hjelmslev puede señalar que "al investigar la línea divisoria entre semiótica y no semiótica, una conclusión poco menos que evidente salta a priori a la vista: los juegos se encuentran cerca de esta frontera, o tal vez en la frontera misma." "Las estructuras semióticas [...] no son juegos." (Hjelmslev, 1984, p. 154. Cf. también p. 156). Al reconocer los procedimientos rituales que desconstruyen las estructuras significantes, habría que pensar en la posibilidad de que la significación tiene la capacidad de revertirse sobre si misma, hasta disolverse. $\mathrm{Al}$ respecto, Mier afirma que el juego es " $u$ acto semiótico negativo [las cursivas son mías] en el cual se anula todo proceso de semiosis, en una especie de gesto que cancela la significación, la revierte, se vuelvè sobre ella para disiparla en el goce de ese tránsito en los bordes de la regulación. Es en el juego donde la significación muestra su poder radical, que es disiparse a si misma" (Mier, 1999, p. 75), a la vez que la cancelación de la significación hace emerger nuevos signos: 
La destrucción de los signos engendra a su vez signos de esa destrucción, huellas de lo que se extinguió,"la propia metamorfosis de los signos engendra significación; la experiencia se convierte en un punto de partida y un eslabón de la semiosis. (Mier; 2000, p. 136).

El tema de la emergencia del significado en la fase liminar del rito figura en la obra de Turner como una inquietud central y, reconociendo el lugar de la experiencia, busca responder a ésta con base en la estructura temporal de la vivencia de Wilhelm Dilthey que comprende cinco momentos: (1) un núcleo perceptual intenso cargado de placer o dolor, seguido por (2) la evocación de imágenes claramente perfiladas de vivencias del pasado, (3) la plena reviviscencia de los acontecimientos pasados con los sentimientos originalmente enlazados, (4) la generación de significado por medio de una reflexión sensible sobre las conexiones entre los acontecimientos pasados y presentes, hasta concluir (5) en la expresión y comunicación de la vivencia. (Turner, 1989, pp. 16-19). Una de las razones por las cuales Turner se adhiere a este planteamiento diltheyiano; me parece, es el factor de reflexividad en el cual el antropólogo insiste repetidas veces,. suponiendo una relación dialéctica entre un estado del fluir que caracteriza la liminaridad y el surgimiento de la reflexividad y autorreflexividad, en la cual se instituye el significado de lo vivido: Sin embargo, es justamente esta supuesta dialéctica la que requiere de. un refinamiento analítico y, en busca de éste, me oriento a continuación en la propuesta semiótica de Peirce. -

La estructura temporal de la vivencia que apunta a una armonización musical de los valores del presente abigarrado en una referencia al pasado, por un lado, rebasa el ámbito propiamente dicho de la vivencia y, por otro, resume en lo que Dilthey llama su primer momento una serie de elementos que hay que distinguir: El núcleo intenso cargado de placer o dolor parece ábarcar indistintamente el abandono del actor ritual a un estado del sentir, la duración del propio estado del sentir, el quebrantamiento de éste y:la emoción que de ahí emerge. Hemos tratado de describir el abandono con base en los medios desarticuladores del ritual, poniendo el énfasis en el juego como "acto. semiótico negativo". El sentir y la quiebra de éste nos proponemos 
abordar en una lectura concienzuda de algunos textos de la obra de Peirce quien, con respecto a la emoción, señala que ésta surge posterior al estado del sentir y a la sensación. La emoción implica reacciones del cuerpo que se manifiestan en gestos de agrado o desagrado; incluso puede ser determinada ya por el pensamiento. La sensación ayuda a suministrar la información al conocimiento, en cambio, la emoción "se incórpora mucho más tarde", "mucho después del momento inicial de la cognición de su objeto" (Peirce, 1988, p. 108).

Los demás momentos de la estructura de la vivencia, a mi parecer, pertenecen ya al ámbito de la narrativización de la experiencia, donde ésta, en la particular definición peirciana poco o nada tiene que ver con la vivencia diltheyiana. La narrativización está claramente presente en el énfasis en la dimensión del pasado, lo cual le permite a Turner retomarla noción de restaúración del pasado de Schechner y resumir en ésta la génesis del significado (Turner, 1985, pp. 213-214; Schechner, 1988, pp. $40-43,51 \mathrm{ss}$ ). Sin embargo, será preciso mostrar la presencia de una temporalidad más compleja. Habrá que distinguir entre un pasado narrativo -el pasado vivido por otros-que, en el sentido expuesto por Abrahams, remitiría a una suerte de experiencia típica, y un pasado vivido; y habrá que distinguir también con respecto a este último un pasado vivido más o menos distante, pero en cualquier caso sometido ya a los procedimièntos de narrativización, el pasado narrado que suministra los medios sígnicos para pasar de la presencia de lo vivido a la representación, al cual, a mi parecer, se refiere Dilthey, y un pasado vivido, el estado de un sentir que apenas ha sido, pero del cual no queda más que un residuo o una huella por la fuerza destructiva de la experiencia y el distanciamiento temporal que ésta introduce, tal como Peirce la define. Es a este pasado vivido al cual -estrictamente hablando- se aplicaría la idea turneriana de restauración del pasado; al asignar significado a la experiencia, clasificarla dentro del repertorio culturalmente disponible y otorgarle persistencia por la vía de la memoria. Al nombrar el "eso originario" o algo "insignificante" del sentir del cual queda sólo "un residuo" temporalmente distante, se convierte en pasado narrado, producto de un patrón cultural y, a su vez, molde para las interpretaciones y representaciones de experiencias tuturas, propias o ajenas. La narración "transforma la fisonomia irreductible del quebrantamiento", lo arranca del olvido y lo impregna de memoria (Mier; 1999, p. 82). 
- El, acontecimiento se preserva en la memoria marcada violentamente con los signos de su propia desaparición, el acontecimiento sólo es tolerable cuando ha sido recobrado

$\therefore$. "por el consuelo de la certidumbre. (Ibid., p. 91)

* Según la semiótica peirciana, el signo se engendra en una presencia, entendiendo ésta como algo simultáneamente estructurado y no estructurado, como copresencia de cualidades distintas de significación. El signo emerge de la vaguedad de un fondo en el cual los principios lógicos de la identidad, la no-contradicción y el tercero. excluido no tienen vigencia. El lugar lógico de la vaguedad corresponde a la primera de las categorías de la faneroscopia que fundamenta simultáneamente los modos de ser de lo Real y de los procesos del conocimiento $y_{6}$ la significación que comportan intrínsecamente una dimensión temporal. Las categorías o fanerones de Primeridad, Segundidad y Terceridad se caracterizan por una heterogeneidad señalada en los términos respectivos de Posibilidad, Actualidad (Existencia) y Necesidad, y corresponden a las nociones de estado del sentir, experiencia (sensación) y hábito (representación), sobre las cuales versan las siguientes exposiciones en busca de una mayor claridad sobre la génesis del significado.

.Peircè advierte que no se trata de "exagerar el elemento de Primeridad" que haría creer que "la bondad del razonar consiste en esta sola satisfacción estética. "Esto podría ser si fuéramos dioses y no estuviéramoś sujetos a la fuerza dè la experiencia. "(Peirce, 1.988, p. 128). Si bien la Primeridad es del dominio de la cualidad y el sentir, "la Terceridad fluye a nosotros por todas las avenidas de los sentidos" (Ibid., p. 127)..$^{12}$ Es pues, en la representación y en el. pensamiento que el ser humano se construye, en el uso de los signos, lo cual le permite a Peirce afirmar que "la palabra o signo que utiliza

12. Cabe señalar que, en la tríada de las ciencias normativas, la estética ocupa el lugar de la Primeridad, la ética, el de la Segundidad y la lógica, él de la Terceridad. Cf. Esposito, 1999, p. 10. Cf. también la introducción de Helmut Pape a Peirce (1986, p. 7,1 ): la tríada mayor se compone de matemáticas, filosofía y ciencias especiales, y la filosofía se divide entre fenomenologia (o faneroscopia), ciencias normativas y metafísica, las ciencias normativas comprenden la estética, la ética y la lógica." 
el hombre es el hombre mismo." "Mi lenguaje es la suma total de mí mismo; pues el hombre es el pensamiento."(Peirce, 1988, p. 121). El hombre es producto de un trabajo de sentido, entendiendo por éste una creación infinita de sentido, de manera tal que Peirce puede plantear que el grado más elevado de realidad sólo se alcanza por medio de signos (Peirce, 1977, p. 23), por medio de una serie de representaciones las cuales, sin embargo, presuponen lógicamente un estado del sentir que se caracteriza por la presencia de relaciones no eficientes. $\mathrm{La}$ función esencial de un signo, entonces, es hacer eficientes estas relaciones no eficientes, esto ès, se trata de fijar una regla general e instituir un hábito por medio del cual las relaciones puedan actuar.(Ibid., p. 31)

Precisamos, pues, reconocer la primacía lógica y ontológica de la Primeridad la cual, sin embargo, sería una presencia muda, si el proceso de semiosis se detuviera en ella, supuesto que, por lo demás, fuese impensable e irrepresentable. Por otra parte, y esto me parece esencial, hay que tomar en cuenta que la primacía fenomenológica le corresponde a la Segundidad y junto con ella, a la experiencia. Paradójicamente, no hubiese sucedido nada si no fuese por la experiencia, en la cual el sentir se destruye, y tampoco habría un algo, aunque sea sólo un residuo o una huella, que pudiese significarse.

La categoría de la Primeridad es la de la cualidad y el sentir, donde Peirce hace la aclaración de que una idea de Primeridad es una impresión total, no analizada, no pensada como un hecho, sino una mera cualidad, esto es, una Posibilidad positiva y simple de un aparecer (Ibid., p. 25). El Primero se describe en términos de frescura, inmediatez, espontaneidad, originalidad, presencia, evanescencia y novedad. La idea del Primero es tan frágil que no se la puede tocar sin destruirla, ya que, con sólo äfirmar el Primero, éste ya deja su inocencia característica porque la afirmación implica siempre y al mismo tiempo, negar un algo otro (Peirce, 1978, pp. 72-73). El sentir se entiende como absolutamente simple e indiviso, como una presencia inmediata e instantánea. Aun considerando que el sentir puede estar presente durante un lapso de tiempo, está presente indivisiblemente en todos los momentos de ese tiempo. El sentir no es un acontecimiento o un sobrevenir sino un estado que es íntegramente lo que es en todos los momentos, no importa cuál sea la duración (Ibid., pp. 83-88). 
1. Según Peirce, no hay conciencia en el sentir que, por lo demás, es un continuum, to cual me remite al planteamiento de Maurice Mérleau-Ponty de que:el sentir pertenece a un estrato originario, antepredicativo; que es anterior a la sensación en tanto que ésta presupone un trabajo de abstracción y una división de los sentidos, mientras que'aquél se presenta como una sinestesia en la cual los. sentidos se comunican. La idèa de sinestesia le permite al filósofo plantear la idea; por ejemplo, de "ver" los sonidos y "oír" los colores $o$, con relación à la percepción del espacio, vislumbirar la unidad intencional del espacio por la vía de una convergencia éntre los diversos dominios sensoriales que posibilitan pënsar no sólo en un espacio visual y táctil, sino también en un espacio auditivo. La sinestesia se entiende a la manera de un fluir de cualidades que se vincula con el movimiento genèral del ser-en-el-mund̆o que és un "movimiento virtual". "Lốs sentidos se traducen el uno al otro sin necesidad de intérprete, se. comprenden el uno al otro sin tener que pasar por la idea. "(MerleauPonty, 1994, p. 249). En términos de Peirce, la cualidad del sentir es. Posibilidad pura, es puro poder-ser no necesariainente realizado, por . lo tanto es general, donde, sin embargo, hay que distinguir.la generalidad de la Posibilidad de la generalidad del pensamiento, propia de la Terceridad. Aun siendo indiviso, el sentir se caracteriza por una inestabilidad o movilidad, y podría hablarse probablemente de un gradiente o una modulación del sentir en tanto que las cualidades se fundan o se deslizan unas en'otras, ya que no poseen identidades perfectas sino sólo parciales.

- Ahora bien,'Peirce señala que todo lo que decimos sobre las cualidades es cierto después de reflexionar sobre ellas, lo cual tiene que ver con el carácter frágil de la Primeridad, arriba mencionado, e involucra la Terceridad én tanto que pensamiento que presupone la aprehensión de las cualidades por mediö de la sensación que suministra la información. Pero, si bien'la sensación es requisito para la aprehénsión de la cualidad, sin embargo ninguna sensación ni facultad sensorial es requisito para la Posibilidad que es el ser de la cualidad. La.Actualidad ño produce la Posibilidad, sino el mundo ya posee por sí misma la Posibilidad de sénsación, sólo falta que nuestros sentidos quiéran responder a ella (Peirce, 1978, pp. 89-92). 
Para Peirce, el sentir es un estado, no es un acontecimiento o un sobrevenir quie son propios de la experiencia (Peirce, 1988, p. 101). Esto me hace regresar a la cuestión del ritual en sus fases de desconstrucción y construcción de la significación y el intersticio "insignificante" que se inserta en la duración liminar entre ambas fases. Por un lado, probablemente no sea casual que la expresión turneriana que caracteriza la liminaridad como el mundo subjuntivo y de lo. "posible" coincide terminológicamente con la descripción peirciana de la Primeridad como Posibilidad, aunque habría que cuidar la distancia que mide entre la teoría del antropólogo y el pensamiento del filósofo. Para Peirce, la Posibilidad puntualiza una categoría formal de los modos del ser de lo real, mientras que, en el caso de Turner, la formulación en la oposición entre estructura y anti-estructura, supongo que más bien se hace con miras a la substancialidad de las relaciones sociales: lo posible como alternativas concretas que se manifiestan en la negóciación de los proyectos de vida.

Si entendemos la liminaridad como una fractura, una cuestión que se plantea es referente a los momentos de inauguración y consumàción y, entre àmbos, el momento del sobrevenir. Al respecto, me parece interesante la propuesta de Luiz Tatit que insiste en reconocer una dimensión temporal que el autor esquematiza en términos de duraciones, según los cuales la continuidad del que hacer cotidiano y rutinario -la continuación de la continuación-se ve interrumpida por un acontecimiento sorprendente -la parada de la continuación-que da lugár a una fractura -la continuación de la parada (Tatit, 1999, pp. 198199). Por lo demás, el autor hace hincapié en el hecho de que la experiencia. estética ciertamente se construye de manera retroactiva; lo cual, según su esquema hace suponer que el sobrevenir se localiza en el momento de la sorpresa que se distiende en la duración de la captura estética. Creo que ésta es una postura compartida por la mayoría de los semiotistas atraídos por las vetas de interpretación que ofrece la "imperfección" greimasiana, aun cuando explícitamente no tematizan la dimensión temporal. Sin embargo; si proseguimos con el esquema de Tatit, éste, en su formulación binaria, debería conducir consecuentemente a la extraña caracterización de una parada de la parada que retorna a la continuación de la continuación, la cual -si algo significa- sólo puede ser el sobresalto, el momento del sobrevenir. Por lo tanto, no es el sentir el que sobreviene, sino éste más 
bien se desliza o escurre en el sujeto arrastrado por el juego de las inversiones $\mathrm{y}$ la ritmicidad de las acciones rituales. La saturación del campo de los significantes borra la significación y abre un horizonte del sentir a la deriva. Es decir, no hay mediación entre la Terceridad y la Primeridad, sino, si la significación tiene la capacidad de disiparse a sí misma, se instala - a través de su propio derrumbe-en la Primeridad del ser del mundo que posee la Posibilidad para una sensación. Aunque, si tomamos en cuenta una anotación de Peirce en relación con las Letras estéticas de Friedrich Schiller, podríamos considerar los juegos rituales como Segundidad cuya acción-reacción se prolonga en una tensión -y por ello, la ansiedad mencionada por Lévi-Strauss-la cual se disuelve en la vaguedad de un estado del sentir.

'En las exposiciones anteriores he sido lo más cuidadosa posible en el uso de las nociones de sentir y sensación porque, por un lado; se. nutren de la distinción de Merleau-Ponty entre una síntesis perceptiva intencional -no nocional-y una percepción discreta que presupone una atención y, poi otro, remiten a las categorías respectivas de Primeridad y Segundidad del pensamiento de Peirce quien hace un uso diferenciado de los términos de feeling (sentir) y sensation (sensación). ${ }^{13}$ Para.Peirce (1988),

todo pensamiento, en la medida en que es un sentir de un. tipo particular, es simplemente un hecho último inexplicable.

* Entonces, nunca podemos pensar, 'Esto me es presente', ya. que antes de que tengamos tiempo de hacer este reflexionar - la sensación ya ha pasado, y, por otro lado, una vez pasada, no podemos ya ninca recuperar la cualidad del sentir tal . como era en y por sí misma.(p. 104)

13. En los párrafos siguientes, al citar los textos reunidos en El hombre, un signo, los he. cotejado con el original en inglés. El traductor ușa indiscriminadamente las palabras españolas de sentir, śensación y sèntimiento para el término inglés de feeling. Me he tomado la libertad de sustituir los términos de sensación y sentimiento por sentir (estado del sentir) cuando éstos corresponden a feeling. Cuando hago estas correcciones, uso cursivas para indicar la alteración de la cita. Lá palabra sensación, la conservo pára el término inglés de sensation. Cf. Peirce 1991, pp. 28-55; pp. 312333, e Peirce, 1998, segundo tomo, pp. 346-359. 
Todo lo que podemos averiguar observando directamente la conciencia son cualidades del sentir, y, no tal como se sienten, sino tal como se agrupan después de ser sentidas (el subrayado es mío) (p. 373).

Uno [...] es consciente de forma inmediata de sus estados del sentir; pero no de que sean estados del sentir de un ego. $\mathrm{El}$ mí-mismo (self) sólo së infiere. En el presente no hay tiempo en absoluto para inferencia alguna, $y$, menos que nada, para una inferencia relativa a estè mismo instante. (p. 249).

Los fragmentos citados de la obra de Peirce muestran que hay una distancia que mide entre el sentir y la sensación y que esa es de orden temporal, la génesis de la significación, por lo tanto, comporta intrínsecamente tiempo. Dicho de otra manera, según Peirce, dos pensamientos no caben en un mismo instante, implican, pues, necesariamente la segregación de dimensiones temporales, esto es, las dimensiones de pasado y presente. Sin embargo, en principio, el tiempo se entiende como un continuum que involucra un cambio de cualidades, pertenece, pues, a la Primeridad, y resulta particularmente interesante que Peirce al respecto parece hacer afirmaciones contradictorias que vinculan o bien el tiempo total, o el presente o el pasado con la Primeridad, a la vez que el presente y el pasado también se mencionan en relación con la Segundidad. Más allá de estas consideraciones vacilantes, al parecer, sólo al futuro le corresponde un lugar preciso, en tanto que identificado repetidas veces y fuera de toda duda con la Terceridad. No'obstante, las anotaciones cambiantes me llevan a vislumbrar que las contradicciones más bien son aparentes y reflejan el carácter complejo de la vinculación entre temporalidad y significación que tiene que ver con el lugar fenomenológicamente dominante de la Segundidad, explicitada en términos de fuerza bruta o acción-reacción que implica una dimensión relacional cuyo rasgo esencial es el de la afección o afectación:

Pasado, presente y futuro se constituyen a partir de [... una] asimetría de la significación del tiempo cuyo eje inequívoco es el presente." "La asimetría tiene una fuente: 
la capacidad de afectación (afección) de los signos. Y esta capacidad de afectación imprime en la serie de las sensaciones, en la estructura de la experiencia, en la. formación de los hábitos, un movimiento irreversible. (Mier, 2000, p. 135).

La Segundidad es el lugar de reconocimiento del tiempo:Peirce Señala que el tiempo "sólo puede identificarse por bruta compulsión" (Peirce,' 1988, p. 250), esto es; en la experiencia, la cual se define como la conciencia de la acción de un nuevo sentir al destruir el sentir precedénte. Según Peircè, una impresión de quietud, por ejemplo, puede ser üna idea de Primeridad, una cualidad del sentir. Si el silencio se rompe por medio de un ruido que implica un sobresalto de la persona sumergida en el sentir, estamó frente a una experiencia. Mientras la persona está sumida en la inercia de ese silencio, está permeada por el estado del sentir, sin embargo el ruido que llega a pesar de la personá, introduce la Segundidad, en tanto que provoca una acción-reacción, una fuerza-resistencia, que instala las instancias de ego y non-ego, donde el ser del non-ego puède ser objeto de la conciencia directa (Peirce, 1977,·p. '26. Cf. tämbién Peirce, 1988, p. 129). Consecuentemente, Peirce define la experiencia como lä conciencia de la acción de un nuevo sëntir al momento de destruir un sentir precedente(Peirce, 1977, p. 26). Mier comenta al respecto:

- Esta conciencia significa la duración de las sensaciones y su límite, es memoria de la.destrucción, de esa irrupción del 'signo a costa de la destrucción de otro signo. La memoria de los signos no es simplemente la decantación de una semiosis, de una aprehensión y significación de los hechos. La semiosis en si misma aparece asi como un recurso de la conciencia, pero también como una semiosis autorreflexiva de esa conciencia. La significación, levantada sobre la experiencia, se funda en la.destrucción de los signos, pero es también significación "duradera de esa experiencia de destrucción.(Mier, 2000, p. 136) 
Peirce plantea un flujo continuo de la percepción que, de manera repentina, en un instante, puede caracterizarse por una ahoridad, que hace emerger una imagen extraordinariamente detallada y clara, la cual identifico como "sensación". Al parecer, la sensación coincide con el momento inicial de la construcción del conocimiento, designado por Peirce como percepto, esto es, el objeto tal como se percibe en un acto singular de la perceppción. (Peirce, 1990, p. 177). En sus obras tempranas, Peirce señala que la sensación no es ni meramente arbitraria, ni puramente necesaria. Las sensaciones existen en sí mismas, donde la existencia se nos presenta como actualidad, quiere decir, que es más que mera posibilidad y que es menos que realidad necesaria. (Esposito, 1999, p. 6). ."Existencia es reacción, y el juicio perceptivo es el producto cognitivo de una reacción.".(Peirce, 1988, p. 125). Todas las ideas surgen en juicios $y$; cuando estas ideas son sensaciones, enseguida causan otras ideas y se conectan con éstas en los juicios (Peirce, 1986, p.107). Con base en lo anteriormente dicho, dedicaré los siguientes párrafos al ensayo lo más coherente posible de presentar algunos fragmentos de los textos peircianos sobre sus concepciones del tiempo en estrecha relación con las categorías de Primeridad, Segundidad y Terceridad; Creo mostrar con ello que las asociaciones aparentemente vacilantes entre las categorías de la faneroscopia y las dimensiones temporales tienen que ver con el carácter esencialmente procesal de la semiosis.

La semiosis parte de un sentir viviente que se inscribe en un continuum de duración infinitesimal "pero, con todo, abarcando innumerables partes": las cuales, de manera asociativa, forman una idea general de carácter ilimitado que señala "una vaga posibilidad que hay algo más presente" y que muestra que la idea "se modifica gradualmente y se conforma a otra." Peirce explicita al respecto tres elementos que integran una idea:

El primero es su cualidad intrínseca como sentir. El segundo es la energía con la que afecta a otras ideas, una energía que es finita en el aqui-y-ahora de la sensación inmediata, finita y relativa en la proximidad del pasado. El tercer elemento es la tendencia de una idea a traer consigo otras ideas. (Peirce, 1988, pp. 267-268). 
Con ello, la idea en tanto que pensamiento-signo, comporta una mutabilidad por la participación intrínseca de las categorías de Primeridad, Segundidad y Terceridad que implican tiempo. La idea general es un sentir viviente,

no es una cosa que se pueda captar en un instante. Se ha de vivir en el tiempo; y tampoco ningún tiempo finito puede abarcarla en toda su plenitud. Con todo, se encuentra presente y viva en cada intervalo infinitesimal, aunque especialmente coloreada por las sensaciones inmediatas de aquel momento. [...] Una idea general, viva y consciente ahora, es ya determinante de futuros actos, en una medida de la que ahora no es consciente. Según Peirce, la referencia al futuro es un elemento esencial puesto que implica un principio de crecimiento que es un elemento primordial del universo y de la significación (Ibid., p. 275). ${ }^{14}$

Incluso, la significancia del pensamiento y de su racionalidad está en la referencia al futuro, un futuro posible, que implica la noción de un summum bonum o una armonía final que es el fundamento de una interpretación racional hacia un pensamiento futuro (Peirce, 1988, p. 108), contrariamente al planteo diltheyiano que buscaba la armonización en la referencia al pasado.

El sentir tiene una continuidad intensiva -referida al tiempoy una extensión espacial. Peirce argumenta que "el tiempo supone lógicamente una disposición continua de la intensidad del sentir" (Peirce, 1991, p. 266) y

el tiempo, lógicamente, implica con su continuidad algún otro tipo distinto de continuidad que el suyo propio. El tiempo,

14. La idea de crecimiento tiene que ver con el planteo peircianio de una teoria lógica de la evolución que no implica un acercamiento al darwinismo, ni tampoco una asociación con un optimismo de progreso o un desarrollo creciente de complejidad a partir del supuesto de un estado simple. Según Peirce, los signos crecen y, si hay signos, entonces el universo es teleológico. Distingue entre causación eficiente y causación final, y considera que estamos correctamente acostumbrados a pensar que las causas preceden a los efectos, sin embargo, la acción mental parece ser la extraordinaria excepción de estas leyes que ordinariamente se aplican a los procesos mecánicos. Cf. Esposito, op. cit., pp. 2, 3, 6 y 8. 
en tanto forma universal de cambio, no puede existir a menos que haya algo que experimente cambio, y para experimentar un cambio continuo en el tiempo tiene que haber una continuidad de las cualidades cambiables.(Ibid., pp. 265$266)^{15}$

Previamente, en el mismo texto, Peirce precisa que "la continuidad supone cantidades infinitesimales." (Peirce, 1988, p. 263) lo cual le permite ahora concluir que

se sigue, pues, de la definición de continuidad, que cuando está presente cualquier tipo particular de sentir está presente un continuo infinitesimal de todos los estados del sentir, que difiere de aquél infinitesimalmente. (Ibid., p. 266).

El continuum es el fundamento para describir el tiempo íntegro y la duración del sentir presente, lo cual le lleva a Peirce a afirmar que el tiempo en su totalidad ilustra la Primeridad (Peirce, 1990, p. 151) y a distinguir entre "instante" $\mathrm{y}$ "momento", utilizando el primer término "para significar un punto del tiempo, y momento para significar una duración infinitesimal. "(Peirce, 1988, p. 255). Al parecer, semejante a la distinción entre dos órdenes de pasado -uno vivido y otro narrado-

15. La cita continúa: "No podemos fórmarnos ahora más que una débil concepción de la continuidad de las cualidades intrinsecas del sentir. El desarrollo de la mente humana ha extinguido prácticamente todas las sensaciones [feelings], excepto unos pocos tipos esporádicos, sonido, colores, olores, calor, etc., que aparecen ahora como desconectados y separados. En el caso de los colores hay una difusión tridimensional de las sensaciones [feelings]. Originalmente, todas las sensaciones [feelings] pueden haber estado conexionadas de la misma manera, y el supuesto es que el número de dimensiones era interminable. Pues, el desarrollo implica esencialmente una limitación de las posibilidades." (p. 266) Me parece una cita extraordinaria para introducir en la filosofía natural de Peirce que, con base en las categorías de la faneroscopia plantea el mundo como continuum (sinejismo), la irrupción del azar en el continuum (tijismo) y la teleología del mundo orientado hacia el summum bonum (agapismo). Cfr. la introducción de Pape al primer tomo de Peirce (1986), pp. 48-55. Véase también Peirce "Inmortality in the Light of Synechism (1893)"; The Essential Peirce, op. cit., tomo II, pp: 1-3; y unas breves anotaciones sobre sinejismo y tijismo en "La ley de la mente", (Peirce,1988, pp. 251-252 y.278). Hay que recalcar que las referencias al sinejismo y tijismo se encuentran en la introducción y conclusión del texto que, en su totalidad, es presentado por Peirce como una explicación del sinejismo, abordando el problema de la continuidad del tiempo y de las ideas. 
y dos órdenes de futuro - uno necesario y otro contingente-; lo que está en juego aquí es el supuesto de una diferenciación de dos instancias del presente. Puesto que "là cońciencia esencialmente ocupa tiempo", el presente se plantea como momento, esto es, como duración infinitesimal que, por lo tanto, le permite a Peirce poner a consideración que " $\mathrm{el}$ presente es mitad pasado [vivido] y mitad por venir" (Ibid., p. 264) ${ }^{16}$ ". $\mathrm{El}$ presente se caracteriza por una asimetría y puede plantearse como un presente distendido que, a su vez, incluye el instante presente en tanto que el sentir inmediato es el sentir "a través de una duración infinitesimal que contiene al presente instante" [las cursivas son mías]. (Peirce, 1988, p. 264). Es en este instante donde la idea de una "dinámica de la desaparición" (Mier, 2000, p. 138) cobra. su importancia ya que Peirce señala que el presente como instante sólo puede conocerse como el último lapso del pasado, puesto que es la única manera como podemos conocer el presente - por bruta compulsión, como decía -, donde el pasado, consecuentemente, podría considerarse como algo que por sí mismo es una Primeridad (Peirce, 1990,p. 151). Se trata, pues, de un pasado vivido o de un "residuo emblemático de lo vivido", ya que "un vasto repertorio de lo presente desaparecerá sin dejar huella; sobrevivirá de ello, acaso, la pura memoria de la afección sin residuos: memoria de la futilidad de la percepción, de su transitoriedad, y, al mismo tiempo, de su fuerza de discriminación, de su violencia selectiva -eso que Peirce habia llamado la prescisión como condición del juicio" (Mier, 2000, p. 137), esto es, la prescisión como primera aprehensión del objeto a

16. Anteriormente, Peirce expone que una idea pasada puede estar presente "por percepción directa". "Estar presente tiene que ser ipso facto presente. Es decir, no puede ser completamente pasada; sólo puede estar yéndose, infinitesimalmente pasada, menos pasada que cualquier fecha pasada asignable. Llegamos, así, a la conclúsión de que el presente está relacionado con el pasado por una serie de pasos reales infinitesimales." "La conciencia tiene que abarcar necesariamente un intervalo de tiempo; pues, de no ser así, no podríamos obtener ningún conocimiento del tiempo [...] ninguna concepción en absoluto. Estamos, por tanto, obligados a afirmar que somos inmediatamente conscientes a través de un intervalo infinitesimal de tiempo." "En un intervalo infinitesimal percibimos directamente la secuencia temporal de su comienzo, mitad y fin". "A este intervalo le sigue otro cuyo comienzo es la mitad del anterior, y cuya mitad es el fin de aquél." "A partír de estas dos percepciones inmediatas obtenemos una percepción mediata, o inferencial, de la relación de los cuatro instantes." lbid., pp. 254-255. 
partir de la cual se establecen las diferencias por medio de la abstracción.

El umbral entre pasado y futuro o el instante presente es, según Peirce, algo inescrutable; lo describe como una "muerte viviente" en la cual tiene lugar un renacimiento, o como un "estado naciente entre lo determinado y lo indeterminado" (Peirce, 1988, p. 249). A1 interrogarse acerca de la manera como el presente afecta a la conducta, que no sólo se refière al hacer práctico sino también al pensamiento; la reflexión, la representación y la significación, Peirce señala que la actitud del instante presente "sólo puede ser una actitud conativa. La conciencia del presente es [...] la de una lucha por lo que será; $y$, por tanto, salimos de su estudio con una creencia confirmada de que es el estado naciente de lo Actual" (Ibid., p. 250) o de lo Existente. Con ello, se introduce la categoría de la Segundidad la cual se describe como acción bruta por carecer de autocontrol, o como esfuèrzo sin finalidad, aclarando a su vez de que no se trata de un "sentir" sino de la "experiencia" de un esfuerzo, là cual no puede existir sin la experiencia de una resistencia (Peirce,1977, pp. 25 y 26). El instante presente como lapso último del pasado vivido $\mathrm{y}$, por lo tanto, relacionado con el pasado por medio de una serie de pasos. infinitesimales, pues, es el "momento" del sobrevenir o acontecimiento, en el cual el sentir precedente se destruye por medio de la irrupción de un nuevo sentir. Es el momento de la conciencia inmediata de la sensación en el presente, yéndose infinitesimalmente hacia el pasado, mientras que el sentir no involucra conciencia alguna y abarca un presente que potencialmente es el tiempo en su totalidad.

La Segundidad, a su vez, se aplica al pasado en tanto que Existente que afecta a la conducta del presente:

El pasado consta de la suma de faits accomplis, y este acabamiento es el modo existencial del tiempo. Pues el pasado nos afecta realmente. [...] El modo del pasado es el de Actualidad (Peirce, 1988, p. 247).

El pasado repercute en el ser humano porque éste basa su "conducta en hechos ya conocidos", esto es, en la memoria y, en este sentido, "el pasado es el depósito de todo nuestro conocimiento" 
(Ibid.p. 249). El pasado no puede reformarse, puesto que su memoria subsiste y no se puede eliminar ningún modo de expresión de ella, sólo se pueden agregar maneras, suplementarias de expresar el mismo significado, y Peirce agrega al respecto que la multiplicación $y$ proliferación de modos equivalentes de expresión es una carga (Peirce, 1977 , p. 20). Ahora bien,"la memoria de este pasado que afecta a la conducta presente y, por esta vía, sugiere la conducta del futuro, esto es, la posibilidad de una conducta deliberada'y autocontrolable, 'se refiere a la memoria del pasado vivido, distinto del pasado como pura narratividad que "se encuentra más allá de la memoria" (Peirce, 1988, p. 249) y atáñe a la conducta a manera de una regla o ley. Podría decirse que el pasado como pura narratividad comporta un cierto rasgo de futuridad, ya que Peirce define el futuro como la dimensión temporal que "no es Actual", por lo tanto no hay afección como en el caso de la memoria del pasado vivido "excepto a través de la idea" del futuro y del pasado narrativo -, "es decir, tal como actúa una ley". Cabría preguntarse, incluso, si a ese pasado narrativo se aplica también la distinción que Peirce hace.con respecto al carácter necesario o contingente del futuro: "En èl futuro, todo está, o destinado, es decir, dado ya necesariamente, o indecidido, el futuro contingente de Aristóteles. "(Ibid., pp. 247-248). En el primer caso se trata de la ley a la cual está sujeta la materia; mientras que, en el segundo, se refiere a la ley de la mente, caracterizada por la incertidumbre que le es esencial puesto que "queda' siempre una cierta cantidad de espontaneidad arbitraria en' su acción, sin lla cual estaria muerta" (Ibid.; p. 273) y puesto que el prësente afectá al futuro en una manera que el sentir viviente aún no es consciente:

La particular concepción de Peirce sobre el sentir como Posibilidad y el carácter destructor de la experiencia induce a interrogar de manera más profunda aceŕca del núcleo vital de las celebraciones rituảles. Lás propuestäs de Peirce me llevan a la pregunta de entender el ritual como un despliegue serial de sucesos con el fin de colocar a los actores rituales en-una posición que les permite recuperar el fundamento ontológico y lógico de la Primeridad, el contacto con el mundo que por sí mismo contiene la Posibilidad de una sensación. En estè sentido, el ritual se presenta como un hacer estético negativo que potencialmente desemboca en la experiencia a partir de la cual se 
construyen los contenidos cognoscitivos. El esquema trifásico de Turner ofrece un marco general para tal comprensión, pero requiere de elementos analíticos adicionales para lograr resultados más finos. Uno de estos elementos lo encuentro en las configuraciones de la ritmicidad que pueden observarse en los distintos eventos rituales y que requerirían de un análisis más minucioso para, a partir de ahí, irse aproximando a una comprensión más íntima que involucra el sentị del actor ritual. Esta ritmicidad se plasma en los pases dancísticos de los borrados de la semana santa cora, inmediatamente observables, que incluso al observador lo apresan por la monotonía que instaura una suerte de estado de sentir que, si bien no se descarga en la violencia de los golpes, pero hace emerger la sospecha de un acontecimiento inminente.

El ritmo introduce una pulsación en el tiempo, las duraciones se dilatan y se contraen, esto es, sensibilizan al sujeto para una vivencia de la temporalidad aun cuando esta experiencia no llega a conciencia sino retroactivamente. $\mathrm{O}$, justamente, porque así sea: de cierta manera, el ritual expresa una voluntad de despedida del pasado, el pasado vivido, pero convertido en pasado narrado por la proliferación de los signos que se han cargado sobre él, manifiesta, pues, una voluntad de despedida como condición de una apertura hacia la contingencia del futuro. Significaría que el ritual efectivamente rompe el curso rutinario, no porque sea sólo una marca de discontinuidad, sino porque en su totalidad muestra o alude a ese momento de la experiencia compulsiva del tiempo y cada acento y cada intervalo al interior del proceso ritual aporta lo suyo.

Las bases teóricas que Peirce ofrece, se ocupan del proceso de la significación y del conocimiento y del fundamento de este proceso. La experiencia guarda en ello un lugar fenomènológicamente preponderante. Como decía Peirce, el mundo ya posee su Posibilidad de sensación y el ritual lo entiendo sobre esta base como.un mecanismo de abrir los sentidos de los actores rituales a que quisieran responder a esa Posibilidad que, en la vida rutinaria, probablemente queda sofocada por la violencia de un exceso de interpretación basada en un automatismo de asignar signos. ${ }^{17}$

17. Podría resultar interesante un análisis del chisme como contraparte de la intención ritual, el chisme que justamente colma una interpretación sobre otra y que podría verse como un proceso de saturación del campo de las significaciones hasta conducir tendencialmente a una implosión, distinta de la explosión de las estructuras significantes que puede producirse por medio del juego. 
La reflexividad y autorreflexividad aducidas por Turner como factores esenciales del ritual no son posibles sino sobre el reconocimiento de la vaguedad que fundamenta el proceso de semiosis que parte del estado del sentir y la emergencia del sentido, el interpretante inmediato, en términos de Peirce, o el efecto total no analizado, esto es, la interpretabilidad como Posibilidad pura. La experiencia actualiza el interpretante dinámico, el significado, en tanto que efecto directo que se produce por un signo sobre un intérprete, y es el momento de la "implantación icónica",(Mier) ,a partir de la cual se engendra la significación, el interpretante final, esto es, la elaboración del efecto pleno como tendencia final (Cf. Peirce, 1977, p. 110). El momento institúyente de la significación se caracteriza por una tensión entre incertidumbre y certeza, la primera introducida por lo que Peirce denomina como grados de degeneración de la Terceridad, y la segunda implicada por el hábito de fijar una creencia.

El segundo grado de degeneración de la Terceridad se define como "operación por la cual brota el pensamiento" la cual no ofrece ni certeza ni justificación. El filósofo señala que es "algo así como conocimiento, de acuerdo a una idea posible. Hầy una instigación, sin incitación alguna. Por ejemplo, usted mira algo y dice: 'Es rojo'. Bien, le pregunto qué justificación tiene para tal juicio. Me contesta: ' $V i$ que era rojo'. En absoluto. Usted no vio nada en lo más mínimo parecido a esto. Usted vio una imagen. No había en ello sujeto, ni predicado alguno. Era justo una imagen indivisa, que no se parecía en nada a una proposición. Le instigó a su juicio, debido a una posibilidad de pensamiento" (Peirce, 1988, p. 169). Al parecer, el interpretante en tanto que Terceridad degenerada en segundo grado es un eslabón que se inserta entre el interpretante inmediato y el dinámico, el instante de la sensación inmediata que hace brotar un juicio perceptivo fuera de controly producto de una reacción. Mientras que el signo según la naturaleza de su interpretante inmediato es una presencia positiva (I) o una señal que se comporta como un imperativo (II) o un interrogativo (III), el instante de instigación al juicio podría interpretarse como el vinculo que posibilita el efecto directo sobre un intérprete. Las caracterizaciones peircianas de los signos según la naturaleza de su interpretante dinámico y còn respecto al modo de expresión del mismo, hacen ver que apenas se están esbózando indicios de un pensamiento activo.y dan cuenta de una complejidad sorprendente de la vaguedad que fundamenta el proceso de percepción. En el primer caso, el 
signó se describe como poético (I), estimulante (II) o impresionante(III) y el signo con respecto al modo de expresión de su interpretante dinámico se desglosa en simpatético (I), coercitivo(II) y persuasivo (III).$^{18} \mathrm{El}$ primer grado de degeneración de la Terceridad, definido por Peirce como “ $l a$ operación 'de ejecutar una intención" (Peirce, 1988, p. 169), parece insertarse entonces entre el interpretante dinámico y el final cuyos signos según la naturaleza del interpretante final se caracterizan como extraño (I), habitual (II) o novedoso (III) y son el punto de partida para la elaboración del efecto pleno que se expresa en los símbolos remáticos, dicentes y argumentales.

El interprètante final implica hábito y tiempo futuro, y me atrevo agregar, la narratividad del pasado, por la suerte de legalidad y futuridad que comporta. Quiere decir que el relato del actor ritual sobre su experiencia se inscribe en el hábito, presupone ya el acto de fijar una creencia o de reafirmarla: Parecería que el hábito opera como instancia post hoc que modifica la experiencia que a su vez implica una modificación por la emergencia de un nuevo sentir y la destrucción del sentir precedente, sin embargo, Peirce señala la presencia del hábito como fuerza afectante desde el propio fundamento del proceso de significación. Dice al respecto:

El sentir, que no ha emergido aún a la conciencia inmediata, es ya afectàble y está ya afectado. De hecho, es hábito, aquello en virtud de lo cual una idea llega a la conciencia presente por medio de un vínculo que había sido ya establecido entre ella y otra idea, mientras estaba aún in futuro. [...] Cuando un sentir surge a la conciencia inmediata aparece siempre ya en la mente como una modificación de un objeto más o menos general. (Peirce, 1988, p. 269).

18. Cf. Peirce "Über das System der existentiellen Graphen als ein Werkzeug zur Erforschung der Logik betrachtet", 1906, in: Peirce 1986,tomo II, p. 404. La numeración en los paréntesis se refiere a la pertenencia de las caracterizaciones según la Primeriduad, Segundidad y Terceridad. En su "Commentaire", Gérard Deledalle describe los signos de la siguiente mánera: hipotético, categórico, relativo (interpiretante inmediato); simpático, chocante, usual (el signo según la naturaleza del interpretante dinámico), gratificación, acción, autocontrol.(el signo con respecto al modo de expresión del interpretante dinámico). Deledalle menciona además la décima tricotomia de la garantía de la expresión triádica del signo con sú objeto dinámico y el interpretante final, en términos de instinto, experiencia y forma o hábito. Cf. Peirce, 1978, pp. 243-244. 
El hábito de fijar una creencia, pues, está presente, por medio de la afección, el rasgo esencial de la relación que caracteriza la experiencia que, como instancia in futuro ya opera en el estado del sentir. Parecería, pues, que la afección del hábito condena a la experiencia a ser experiencia narrada desde el principio si no fuese por la contingencia que caracteriza al futuro y la ley de la mente.

La experiencia entendida en el sentido peirciano como acciónreacción comporta una ambivalencia en tanto que es la condición de posibilidad de conocimiento y, como tal, la garantía para la identidad del significado, pero es a la veez un acontecimiento perturbador por su carácter destructivo que implica potencialmente una quiebra en la cual ocurre una sacudida al apego al universo de los significados establecidos. La experiencia puede entenderse como el borde entre lo indeterminado y lo determinado, implica entonces un momento azaroso; donde me parece relevante subrayar el reconocimiento del azar en su estatuto ontológico, esto es, no como mero límite epistemológico. El azar se vincula con la Segundidad y es la característica del tijismo, según el esquema de la filosofia natural de Peirce, al que lógicamente le precede el sinejismo, el mundo entendido como continuum, y le sigue el agapismo, la ley entendida como orientación hacia un fin último en el sentido de un summum bonum. La experiencia se presenta como un punto de bifurcación entre el apego y la quiebra que, por un lado, tiene que ver con el rasgo intrínseco de la experiencia como acción-reacción y que, por otro, remite a las instancias de Primeridad y. Terceridad entre las cuales se inserta. La fuerza categorial del universo de la significación canónica queda suspendida en el estado del sentir frente a la presencia de un objeto sensible inmerso en el mundo, donde este mundo hay que entenderlo como fuente o reclamo de significación, tal como señala Peirce que el mundo de por sí ya tiene la Posibilidad de una sensación, en la cual todavía no hay lenguaje para nombrar los objetos del mundo. La experiencia implica una discontinuidad lógica y un distanciamiento temporal con respecto al estado del sentir y, por otra parte, la experiencia es también el fundamento de la construcción de las categorías que opera sobre las huellas del sentir y desemboca en lo que Peirce llama el acto de fijar una creencia. Es aquí donde se introduce el apego al universo de los significados, al buscar una inserción coherente de los residuos del sentir en el contexto conocido de las estructuras significantes. Esta 
inserción conlleva el germen y la emergencia de lo nuevo, en la medida que se abre a la duda y la contingencia del futuro. Pero también puede conducir a su contrario, la perpetuación de la significación canónica la cual apunta realmente hacia la imposibilidad de la experiencia ya sea porque la voluntad de fijar una creencia confirme retroactivamente la persistencia de los hábitos, ratifique la constancia de la construcción de asociaciones estables y niegue el elemento perturbador de lo nuevo, ya sea porque los hábitos operen como represión que obstruye la Posibilidad de experiencia, esto es, su condición lógica, el estado del sentir. En términos de Merleau-Ponty, se trata de una contención que imposibilita la suspensión de la narratividad del mundo y, con ello, cierra el acceso a la intencionalidad original del cuerpo fenomenal. La contención involucra un dominio íntegro de estabilidad, en ausencia de cualquier fractura o intersticio, y el orden: imperecederamente estable a su vez implica la reversibilidad de un tiempo espacializado (Merleau-Ponty, 1994,p. 102) ${ }^{19}$. E1 ritual es una lucha contra esta contención que pertenece al régimen del mundo rutinario, y es la suspensión de la narratividad que clasifica las cosas del mundo antes de vivirlas.

\section{Bibliografía}

BABCOCK, B. A. 1978. "Introduction", Babcock (ed.) The reversible world. Symbolic inversion in art and society. Ithaca y Londres: Cornell University Press, pp. 16, 19, 21 y 24.

BARTHES, Roland .1981. Das reich der zeichen. Suhrkamp, Frankfurt am Main.

DORRA, Raúl .1999. “Entre el sentiry el percibir”, in: LANDOWSKI ét al. Semiótica, estesis, estética. São Paulo y Puebla: EDUC y UAP, pp. 253-267.

DUVIGNAUD, Jean .1978. El sacrificio inútil. México: FCE:

19. En contraposición al presente originario con sus horizontes de retenciones y : protenciones, Merleau-Ponty hace referencia ala contención que aparece "como advenimiento de lo impersonal". La contención implanta un tiempo no genuino que conservà un mundo momentáneo del pasado vivido y lo convierte en un modo estable de la vida. "El tiempo impersonal continúa fluyendo, mientras que el tiempo personal "estáatado." 
ESPOSITO, Joseph L. 1999. Peirce's theory of semiosis. University of Toronto: Cyber Semiotic Institute.

HJELMSLEV, Louis .1984. Prolegómenos a una teoria del lenguaje. Madrid: Gredos.

LÉVI-STRAUSS, Claude .1976. Mitológicas IV: el hombre desnudo. México: Siglo XXI.

.1984. El pensamiento salvaje. México: FCE.

LYOTARD, Jean Françoise.1992. Peregrinaciones. Ley, forma, acontecimiento. Madrid: Cátedra.

MERLEAU-PONTY, Maurice .1994. Fenomenología de la percepción. Península, Barcelona.

MIER, Raymundo .1989. "Incidencias: el desconstruccionismo en juego", Acta poética, Revista del Seminario de Poética, núms. 910 , UNAM, Instituto de Investigaciones Filológicas, México, pp. 207-256

.1999. "Reflexiones sobre el juego", José Luis Ramos Ramírez (ed.) . Juego, educación y cultura. México: ENAH, pp. 61-77

.1999. "Semiótica y discordia: el testimonio estético", Landowski et al. Semiótica, estesis, estética. São Paulo y Puebla: EDUC y UAP, pp. 71-97.

.2000. "Tiempo, incertidumbre y afección. Apuntes sobre las concepciones del tiempo en Ch. S. Peirce", GEIST, Ingrid (ed.) La inscripción del tiempo en los textos. Tópicos del Seminario, núm. 4, Universidad Autónoma de Puebla, pp. 131-174.

hermenéutica del juego", RAMIREZ, José Luis Ramos y MARTINEZ, Janeth (eds.) El acto de jugar. México: ENAH, Correo del Maestro y La Vasija, en prensa.

PEIRCE, Charles S. 1868. "Some consecuences of four incapacities", The essential peirce. Selected philosophical writings, tomo I, ed. de Nathan Houser y Christian Kloesel, Indiana University Press, Bloomington e Indianapolis, 1991, pp. 28-55.

.1892. "The law of mind", The essential Peirce. Selected philosophical writings, tomo I. Bloomington e Indianapolis: Indiana University Press, 1991, pp. 312-333.

.1893. "Inmortality in the light of synechism", The essential Peirce selected philosophical writings, tomo II, ed. del Peirce Edition Project, 1998. Bloomington e Indianapolis: Indiana University Press, pp. 1-3. 
1905: "Issues of pragmaticism", The essential Peirce. selected philosophical writings, tomo. II. Bloomington e Indianapolis: Indiana University Press, 1998, pp. 346-359.

-1974. La ciencia de la semiótica, SERCOVICH, Armando (ed.). Buenos Aires: Nueva Visión.

1977. Semiotic and significs. The correspondence between Charles S. Peirce and Victoria Lady Welby, ed. de . HARDWICK, Charles S. (ed.) Bloomington y Londres: Indiana University Press.

Editions du Seuil.

1986. "A quincuncial projection of the sphere", Writings. A chronological edition, vol. 4. Bloomington e Indianapolis: Indiana University Press; pp. 68-71.

1986. Semiotische Schriften, primer tomo, ed. de Christian Kloesel y Helmut Papè, Suhrkamp Verlag, Frankfurt am Main.

.1988. El hombre, un signo (El pragmatismo de Peirce), ed. de José Vericat. Barcelona: Edición Crítica.

1990. Semiotische Schriften, segundo tomo, ed. de Christian Kloesel y Helmut Pape, Suhrkamp Verlag, Frankfurt am Main.

SCHECHNER, Richard .1985. Between theater and anthropology. Filadelfia: University of Pennsylvania Press.

1988. Performance theory, edición revisada y ampliada. Nueva York y Londres: Routledge.

1994. Environmental theater, an expanded new edition including "Six axioms for environmental theater". Nueva York y Londres: Applause Books.

1995. The future of ritual. Writings on culture and performance. Londres y Nueva York: Routledge.

y. Willa Appel (eds.) .1990. By means of performance. Intercultural studies of theatre and ritual. Nueva York, Melbourne, Sydney y Cambridge: Cambridge University Press.

SCHÜTZ, Alfred .1995. El problema de la realidad social. Buenos Aires: Amorrortu Editores.

SINGH, Jaideva 1979. Siva sutras. The yoga of supreme identity. Delhi: Motilal Banarsidass.

TATIT, Luiz 1999: "A duração estética", Landowski et al. Semiótica, estesis, estética. São Paulo y Puebla: EDUC y UAP, pp. 195209. 
TURNER, Víctor W. 1957. Schism and continuity in an African society. A study of Ndembu Village Life, Institute for Social Research, University of Zambia. Manchester: Manchester University Press.

-1974. Dramas, fields and metaphors. Symbolic action in human society. Ithaca y Londres: Cornell University Press.

.1980. La selva de los simbolos. Aspectos del ritual ndembu. Madrid: Siglo XXI.

1985. On the edge of the bush. Anthropology as experience. ed. Edith L. B. Turner. Tucson: The University of Arizona Press.

1988. The anthropology of performance. Nueva York: Performing Arts Journal Publications.

1989. Das ritual. Struktur und anti-struktur, Campus Verlag, Frankfurt am Main y Nueva York

1989. Vom ritual zum theater. Der Ernst des menschlichen Spiels. Frankfurt am Main: Ed. Qumram y Campus Verlag

y Edith L. B. Turner. 1978. Image and pilgrimage in Christian culture: Anthropological perspectives. Nueva York: Columbia University Press.

y Edward M. Bruner (eds.) .1986. The anthropology of experience. Urbana-Chicago: University of Illinois Press.

1989. Vom ritual zum theater. Der Ernst des menschlichen Spiels, Frankfurt am Main y Nueva York: Edition Qumran im Campus Verlag, pp. 16-19. 